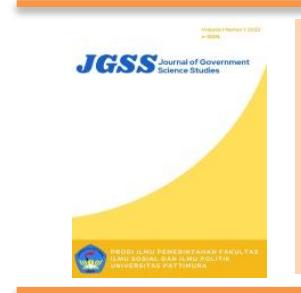

Journal of Government Science Studies

Available online at https://ojs3.unpatti.ac.id/

Vol. 1 No. 1, April 2022, pages: 18-27

e-ISSN: 2827-847X, p-ISSN: 2827-8461

https://doi.org/10.53730

\title{
Strategi Pemenangan Partai Golongan Karya Pada Pemilihan Kepala Daerah Kabupaten Seram Bagian Timur Tahun 2020
}

\author{
Muhammad Nasir Angar1 ${ }^{\text {a }}$, Jusuf Madubun $2^{\mathrm{b}}$, Johan Tehuayo $3^{\mathrm{c}}$ \\ Corespondensi Author e-mail: nasirangar@gmail.com
}

Manuscript submitted: 30-01-2022, Manuscript revised: 31-01-2022, Accepted for publication: 01-02-2022

\begin{abstract}
Keyword:
Winning Strategy 1;

Golkar Party 2;

Regional Election 3;

Abstract: This study is a descriptive qualitative research that aims to know the winning strategy of the Golkar Party in the 2020 Seram Bagian Timur Regency Election. The study results showed that the realization of the Party's programs offered to the community is more inclined to the people's economy, such as in infrastructure, education, and health. The placement of figures was very

Kata Kunci: influential in winning the 2020 Pilkada. The political behavior of the Strategi Pemenangan 1 ; community tends to choose Mukti and Idris because of the candidate's character, vision, and mission on the collective expectations of the community.

Partai Golkar 2; In the Adat leadership, Pak Mukti supports and develops local wisdom and Pemilihan Kepala Daerah 3. inaugurates Adat leaders in Seram Bagian Timur Regency. Pak Mukti's leadership always tends to represent the interests of Adat.
\end{abstract}

\begin{abstract}
Abstrak: Penelitian ini bersifat deskriptif kualitatif dengan tujuan mengetahui strategi pemenangan Partai Golkar pada Pilkada Kabupaten Seram Bagian Timur Tahun 2020. Hasil Penelitian menunjukkan bahwa realisasi program Partai yang ditawarkan kepada masyarakat lebih cenderung pada ekonomi kerakyatan, seperti bidang Infastruktur, pendidikan, dan kesehatan. Penempatan Tokoh atau figur sangat berpengaruh pada pemenangan Pilkada tahun 2020. Perilaku Politik masyarakat cenderung memilih Mukti dan Idris karena dilihat dari ketokohan kandidat dan penawaran visi dan misi yang sesuai dengan ekspektasi masyarakat secara kolektif. Pada kepemimpinan adat, ada keberpihakan Pak Mukti dalam mendukung dan mengembangkan kearifan lokal, serta melantik tokoh-tokoh adat di Kabupaten Seram Bagian Timur. Kepemimpinan Pak Mukti selalu cenderung merepresentasikan kepentingan Adat.
\end{abstract}

\footnotetext{
${ }^{a}$ Universitas Pattimura, Indonesia

${ }^{\mathrm{b}}$ Universitas Pattimura, Indonesia

${ }^{c}$ Universitas Pattimura, Indonesia
} 


\section{Pendahuluan}

Salah satu daerah diIndonesia yang melaksanakan pemilihan kepala daerah (Pilkada) serentak adalah Kabupaten Seram Bagian Timur (SBT). Pilkada serentak 2020, melibatkan berbagai kontestan dan melibatkan strategi-strategi koalisi yang di bangun oleh kekuatankekuatan partai poltik. Pemilukada kabupaten Seram Bagian Timur 2020 kali ini diramaikan oleh calon bupati yang tidak hanya sukses di tingkat kabupaten, bahkan sudah punya nama ditingkat provinsi, seperti calon bupati nomor urut 1 Abdul Mukti Keliobas selaku mantan ketua DPRD, sekaligus ketua DPD II Partai Golongan Karya (Golkar) Kabupaten Seram Bagian Timur 2010-2015 dan juga sebagai bupati petahan 2015-2020, tidak hanya itu calon bupati nomor urut 2 Fachri Husni Alkatiri mantan Anggota DPRD Provinsi Maluku Dapil Kabupaten Seram Bagian Timur, dan juga sebagai wakil bupati petahan mendampingi Abdul Mukti Keliobas 2015-2020, dan calon bupati perempuan nomor urut 3 mantan Anggota DPR RI 2014-2019, bahkan suaminnya mantan bupati Seram Bagian Timur 2 periode.

Persaingan yang sangat ketat pada kontestasi pemilukada tahun ini di kabupaten seram bagian timur, tentunya dari ketiga kandidat ini semua memiliki rekam jejak kepemimpinan dan memiliki pengaruh yang sangat kuat untuk memperoleh dukungan mayoritas demi memenangkan pertarungan pemilukada calon bupati dan wakil bupati Kabupaten Seram Bagian Timur periode 2020-2025.

Tabel 1

REKAPITULASI HASIL PERHITUNGAN SUARA HASIL PLENO KPU-D SERAM BAGIAN TIMUR TAHUN 2020

\begin{tabular}{|c|c|c|c|c|}
\hline No & Pasangan & \multirow[t]{2}{*}{ Partai Pengusung } & Perolehan & Presentase \\
\hline Urut & Calon & & Suara & Perolehan \\
\hline & & & & \\
\hline & Abd Mukti & \multirow[t]{2}{*}{ GOLKAR,PKPI, } & & \\
\hline \multirow[t]{5}{*}{1.} & Keliobas-Idris & & \multirow[t]{2}{*}{31,100} & \multirow[t]{2}{*}{$46 \%$} \\
\hline & & \multirow[t]{2}{*}{ PAN,NASDEM } & & \\
\hline & Rumalutur. & & & \\
\hline & & & & \\
\hline & & PDIP,PKS,PPP, & & \\
\hline \multirow[t]{5}{*}{2} & Fachri H Aktiri- & \multirow[t]{2}{*}{ GERINDRA, } & \multirow[t]{2}{*}{20,939} & \multirow[t]{2}{*}{$31 \%$} \\
\hline & Arobi Kelian & & & \\
\hline & & HANURA,DEMOKRAT,PKB & & \\
\hline & & & & \\
\hline & Hj.Rohani & INDEPENDEN & & \\
\hline \multirow[t]{4}{*}{3.} & Vanath-Ramli & & \multirow[t]{2}{*}{15,555} & \multirow[t]{2}{*}{$23 \%$} \\
\hline & & \multirow[t]{2}{*}{ (E-KTP) } & & \\
\hline & \multirow[t]{2}{*}{ Mahu } & & & \\
\hline & & & & \\
\hline
\end{tabular}




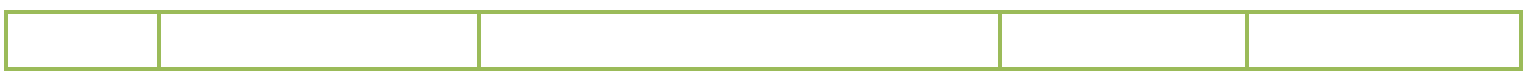

(Sumber: Kpu.Seram Bagian Timur 2020)

Berdasarkan perhitungan suara yang dilakukan oleh Komisi Pemilihan Umum (KPU) Kabupaten Seram Bagian Timur, berdasarkan tabel 1 di atas, bahwasannya pasangan Abdul Mukti Keliobas dan Idris Rumalutur yang di usung oleh partai politik Golongan Karya (Golkar), PKPI, Pantai Amanat Nasional (PAN), dan Nasional Demokrat (Nasdem) mendapatkan suara tertinggi dengan presentase 46\%, sedangkan Pasangan Fachri Husni Alkatiri Dan Arobi Kelian yang di usung oleh Partai Demokrasi Indonesia-Perjuangan (PDIP), Partai Keadilan Sejahtera (PKS), Gerakan Indonesoa Raya (Gerindra), Partai Demokrat, Partai Persatuan Pembangunan (PPP), Partai Hati Nurani Rakyat (Hanura) dan Partai Kebangkitan Bangsa (PKB) berada di posisi kedua dengan presentase suara 31\%,dan yang terkahir pasangan $\mathrm{Hj}$, Rohani Vanath Dan Ramli Mahu yang maju melalui jalur independen berada di posisi ketiga dengan presentase suara 23\%. Dari hasil Rekapitulasi KPU seram bagian timur, pasangan calon kepala daerah dan wakil kepala daerah dengan nomor urut 1 Abdul Mukti Keliobas dan Idris Rumalutur di tetapkan memenangkan pertarungan pemilihan kepala daerah Kabupaten Seram Bagian Timur tahun 2020.

Kemenangan Pasangan Abdul Mukti Keliobas dan Idris Rumalutur tentunya di pengaruhi oleh berbagai macam strategi yang digunakan oleh partai golkar. Merencanakan strategi, pasangan Mukti-Idris mendapatkan dukungan mayoritas bandingkan kedua lawan politiknya. Padahal jika dilihat dari lawan politiknya pasangan Fachri H Alkatiri dan Arobi Kelian yang mengantongi sejumlah rekomendasi partai seperti PKS 3 Kursi, 2 DPRD Kabupaten 1 DPRD Provinsi, Hanura 2 Kursi kabupaten, PDIP 3 Kursi, 1 DPRD Provinsi dan 2 kabupaten, Gerindra 3 Kursi 1 DPRD Provinsi dan 2 Kabupaten, Partai Demokrat 1 Kursi, PKB 1 kursi Dan PPP 1 Kursi Jadi Total 14 Kursi, Yang Dikantongi Fachri Dan Arobi. (sumber www-kabartimurnews-com.cdn.ampproject.org.)

Pasangan Fachri Alkaltiri-Arobi Kelian (Faham), memiliki pengaruh yang signifikan untuk memenangkan pemilihan kepala daerah, karena dilihat berdasarkan koalisi partai pengusung, sudah tentunnya dari ke-14 kursi tersebut, faham mempunyai basis yang sangat kuat, namun dengan mengantongi mayoritas partai politik tidak mengantarkan pasangan Fachri-Arobi pada kemenangan, bisa dilihat berdasarkan hasil rekapitulasi KPU Seram Bagian Timur di atas. Porelehan suara yang dimiliki Pasangan Fahri-Arobi berbanding jauh dengan Pasangan MuktiIdris. Tentunya bukan hal yang mudah dalam memenangkan pertarungan kursi bupati dan wakil bupati tahun 2020. Tentunnnya kemenagan pasangan ADIL ini tidak terlepas dari peran partai pengusung utama yaitu partai golkar.

Salah satu faktor kemenangan Abdul Mukti Keliobas-Idris Rumaluntur (Adil) adalah mesin partai politik yang bagus, hal lain yang di katakan oleh ketua DPD II partai golkar seram bagian timur bapak Agil Rumakat bahwa setiap suksesi pemilu maupun pilkada partai golkar selalu unggul disetiap dapil di kabupaten seram bagian timur, pada pilkada tahun 2015 partai Golkar berhasil memenangkan mukti-fahri, tidak hanya sampai disitu pilkada tahun 2020 kemarin partai golkar sukses memenangkan kandidat yang di usung dalam hal ini Pak mukti Keliobas sebagai kader golkar Kabupaten Seram Bagian timur. Fenomena ini sangat menarik untuk diteliti tentang strategi pemenangan yang dilakukan oleh partai Golkar dalam memenangkan Pasangan yang di usung Abdul Mukti Keliobas Dan Idris Rumalutur pada pilkada seram bagian timur tahun 2020.

\section{Metode Penelitian}

Penulis menggunakan jenis penelitian analisis deskriptif kualitatif yang akan mampu mendeskripsikan secara mendalam dan mendetail terhadap sasaran penelitian. Menurut (Supranto 2000) objek penelitian adalah himpunan elemen yang dapat berupa orang, organisasi

Angar, N. M., Madubun, J., \& Tehuayo, J. (2021). Startegi Pemenangan Partai Golongan Karya Pada Pemilihan Kepada Daerah Kabupaten Seram Bagian Timur Tahun 2020. Journal of Government Science Studies, 1(1). 
atau barang yang akan diteliti. Kemudian dipertegas Anto Dayan (1986), obyek penelitian, adalah pokok persoalan yang hendak diteliti untuk mendapatkan data secara lebih terarah. Adapun Obyek penelitian dalam tulisan ini meliputi: Kantor DPD partai golkar kabupaten seram bagian timur. Menurut Moleong (2007) Kedudukan peneliti dalam penelitian kualitatif adalah ia sekaligus merupakan perencana, pelaksana, pengumpulan data, analisis, penafsir data, pada akhirnya ia menjadi pelapor hasil penelitiannya.

Penyusunan instrumen penunjang menurut Suharsimi Arikunto (1996) mengemukakan pemilihan metode yang akan digunakan peneliti ditentukan oleh tujuan penelitian, sampel penelitian, lokasi, pelaksana, biaya dan waktu, dan data yang ingin diperoleh. Dari tujuan yang telah dikemukakan tersebut, dalam penelitian ini menggunakan metode wawancara dan observasi

\section{Hasil dan Diskusi}

\section{Realisasi Program Partai}

Berbicara mengenai pemilukada yang demokratis, pastinya peranan partai politik tidak terlepas dalam merencanakan strategi pemenangan. berbagai macam strategi yang disiapkan untuk " perang". Perang yang di maksud bukan saling menumpahkan darah, namun peperangan yang demokratis dengan menggunakan program-program unggulan yang di pakai dalam pemilukada. Strategi pemenangan yang d terapkan partai golongan karya lewat program kerja dan tokoh figur politiknya mampu mengantarkan calon yang di usungnya menjadi pemenang dalam pemilihan kepala daerah dan wakil kepala daerah kabupaten seram bagian timur tahun 2020 . Hasil wawancara dengan beberapa pengurus partai golkar seram bagian timur terkait dengan pemanfaatan program kerja yang di tawarkan oleh calon kepada masyarakat,

Platform yag sudah di amanatkan oleh partai merupakan salah satu fatwa yang menjadi landasan kuat bagi calon yang sudah disiapkan oleh partai dalam pesta demokrasi dalam hal ini pemilukada.program-program yang ada bukan harga mati serta karekteristik perwilayaan atau kebutuhan yang mendasar oleh masyarakat secara geografis yang dipakai sebagai isu strategis yang sudah di tetapkan. Tetapi kreatifitas dan inovasi DPD serta figurlah yang akan mengelolah sehingga menjadi isu strategis yang sangat mempengaruhi masyarakat sehingga proses penduangan suara dapat di peroleh sebagai target partai.

Partai Politik (parpol) menurut Miriam Budiardjo merupakan organisasi politik yang menjadi sarana masyarakat untuk menyalurkan aspirasi (Budiarjo, 2006). Di negara-negara berkembang maupun negara-negara maju parpol menjadi ikhtiar yang penting dalam sebuah sistem politik. Pendapat atau aspirasi seseorang atau kelompok akan hilang tak berbekas, apabila tak ditampung dan disalurkan sedemikian rupa sehingga kesimpangsiuran pendapat dalam masyarakat menjadi lebih teratur.

Sebuah Partai dapat ada dengan sungguh-sungguh jika sekurang-kurangnya ada satu kelompok lain yang bersaing (oposisi), yang membedakan Partai dengan organisasi lainnya adalah bahwa partai mempunyai program khusus yang tidak dipunyai organisasi lain, seperti ikut dalam kampanye yang bertujuan mempengaruhi kebijakan.

Selanjutnya Sigmund Neumann masih tentang parpol menegaskan bahwa: parpol adalah organisasi yang artikulatif yang terdiri dari pelaku-pelaku politik yang aktif dalam masyarakat, yaitu mereka yang memusatkan perhatiannya pada menguasai kekuasaan pemerintahan dan yang bersaing untuk memperoleh dukungan rakyat dan beberapa kelompok lain yang mempunyai pandangan yang berbeda. Sehingga demikian parpol merupakan peranatara yang besar yang 
menghubungkan kekuatan-kekuatan dan ideologi sosial dengan lembaga-lembaga pemerintahan yang resmi dan yang mengaitkannya dengan aksi politik di dalam masyarakat politik yang lebih luas.

Bapak Agil Rumakat selaku ketua DPD II partai golkar kabupaten seram bagian timur sekaligus sebagai ketua tim pemenangan Pasangan mukti-idris.

"Beliau mengatakan Program yang ditawarkan Partai golkar sudah tentunya cenderung atau berorintasi kepada kepentingan dan kesejahteraan masyarakat, yang dimana lebih memprioritaskan dari pada aspek perekonomian, pendidikan dan lain sebagainnya, kami berupaya penuh untuk mengimplementasikan program-program partai secara maksimal dan juga strategi yang di gunakan adalah dimana para kader dari semua tingkat structural melakukan pendekatan-pendekatan secara langsung dengan masyarakat, dengan memberikan bantuan-bantual sosial, edukasi, kami selalu hadir dalam memenuhi kebutuhan-kebutuhan masyaraka, dan juga selalu membangun harmonisasi atau hubungan kekeluargaan yang baik dengan masyarakat, dengan cara-cara inilah kami membangun kepercayaan penuh kepada masyarakat. Ungkap Agil rumkakat".

Hal yang sama juga yang di ungkap oleh Bapak Husein Kelilauw selaku Sekretaris Partai Golkar.

"Beliau mengatakan pada prinsipnya sebagai kader partai golkar kami selalu melakukan kegiatan kegiaan partai yang mana sudah tentunnya dapat memberikan implikasi positif terhadap kehidupan masyarakat, karena kita juga ingin menjaga marwah atau nama baik partai, sehingga kita harus kerja eksra dalam merealisasikan program -program partai dan bahkan visi misi kandidat yang diusung partai golkar mukti-idris sebagian besar telah mengakomodir dari visi besar partai golkar yang dimana memperioritaskan kesejahteran masyarkat dari berbagai macam aspek, ekonomi, pendidkan, perikanan,dan pemanfatan sumber daya lainnya".

Dari hasil wawancara di atas dapat dilihat ada banyak sekali strategi yang digunakan dalam upaya menarik hati pemilih dan memenangkan pilkada. adapun dalam hal ini adala strategi door to door tujuan strategi-strategi tersebut adalah dalam rangka memberikan pendidikan politik pada masyarakat serta membentuk citra politik yang positif baik bagi partai maupun bagi calon itu sendiri. Adapun strategi-strategi yang dilakukan salah satunya melalui kegiatan-kegiatan sosial kemasyarakatan seperti pemberian bantuan untuk masyarakat fakir dan miskin, anak yatim, gotong-royong massal. Oleh sebab itu, partai golkar melalui kader-kadernya selalu berupaya untuk memberikan terbaik kepada masyarakat, sehingga partai golkar selalu mendorong dn mendukung pemeritah untuk meningkatkan kesejahteraan masyarakat. Dilain sisi dapat di akui bahwa kecenderungan masyarakat selalu melihat atensi atau kepedulian partai dalam menjawab permasalahan-permasalahan yang ada ditengah-tengah masyarakat.

\section{Penempatan tokoh atau figure}

Sebagai bagian penting dalam kehidupan organisasi partai politik, keberadaan figur menarik untuk dikaji secara akademis. Terutama berkaitan dengan keberadaan dan eksistensi sebuah partai politik. Berbicara tentang kekuatan figur, sebenarnya tidak bisa dilepaskan dari kekuasaan yang dimilikinya. Kekuasaan yang dimilikinya, seorang figur bisa melakukan apa yang menjadi keinginannya, mulai dari mengendalikan internal partai, kebijakan partai, hingga mempengaruhi pemilih untuk memilih partainya.

Angar, N. M., Madubun, J., \& Tehuayo, J. (2021). Startegi Pemenangan Partai Golongan Karya Pada Pemilihan Kepada Daerah Kabupaten Seram Bagian Timur Tahun 2020. Journal of Government Science Studies, 1(1). 
Kaitannya dengan hal di atas, penulis mewawancarai bapak Aagil Rumakat selaku ketua DPD II Partai Golkar Kabupaten Seram Bagian Timur.

"Beliau mengatakan bahwa jika kita bicara tentang pilkada orang pasti lebih cenderung melihat figur atau ketokohan, jadi kita ketahui bersama bahwa partai politik adalah instrumen yang mengantarkan seseorang kandidat berhasil atau tidak berhasil, jadi saya sebagai ketua DPD partai golkar sekaligus ketua TIM pemenangan saya intruksikan kepada seluruh kader baik pada jenjang kabupaten,kecamatan sampai tingkat desa untuk bekerja maksimal untuk memenangkan kandidat yang di usung partai golkar, dan Alhamdulillah perintah ini berjalan sesuai intruski saya, dan para kader golkar bekerja semaksimal mungkin untuk memenangankan pilkada, dan rekomendasi yang keluar kepada pak mukti sendiri, bukan serta merta namun melalui tahapan seefesien mungkin mulai dari pengujian kriteria baik secara normatif dan juga secara internal partai golkar dalam hal ini kami melakukan indentifikasi tokoh, survei elektabilitas tokoh baru kita merekomendasi kader untuk maju pada pilkda dan itu kami dapat pak mukti masih di sukai oleh masyarakat Seram bagian timur".

Hal yang sama juga di katakan sekretaris partai golkar Bapak Husein Klilauw Kabupaten Seram Bagian Timur.

"Beliau mengatakan bahwa syarat seseorang mencalonkan diri sebagai kepala daerah sudah tentunya hal yang pertama dimiliki oleh calon kandidat tersebut adalah harus memenuhi persyaratan yang di keluarkan oleh Komisi Pemelihan Umum (KPU), namun yang terpenting juga adalah bagaimana partai golkar mengintruksikan seluruh kader untuk bekerja maksimal untuk meyakinkan masyarakat untuk memilih kandidat dari partai golkar, dan juga partai golkar merekomendasikan kader yang mencalonkan diri sebagai Anggota legislatif,maupun eksekutif, adalah benar-benar tokoh politik atau figur yang dikenal masyarakat, dan itu dimiliki, oleh kader golkar bapak Abdul mukti keliobas yang satu-satunya figur golkar yang memiliki elketabilitas yang sangat signifikan untuk memenangkan pilkada. bukan hanya bapak mukti namun golkar merekomendasikan bapak idris yang mendampingi bapak mukti sudah tentunya melewati pememenuhan kriteria dari internal partai golkar itu sendiri. dan Alhamdulillah dengan tahapan ini bapak mukti dan idris memenangkan pilkada 2020, yang dimana juga kemenengan ini tidak terlepasoleh kekuatan ekstra dari partai pengusung lainnya".

Kaitannya dengan hal di maksud ada beberapa pakar politik mengartikan fungsi partai sebagi sarana rekrutmen politik. Partai politik mencari dan mengajak orang yang berbakat untuk turut aktif dalam kegiatan politik sebagai anggota partai (political recruitment).

Kampanye Politik

Kegiatan pemilihan umum tidak terlepas dari aktivitas kampanye. Kampanye dan pemilu bagai "dua sisi mata uang " yang tidak bisa dipisahkan satu sama lain. Kampanye adalah sebuah tindakan doktrin bertujuan mendapatkan pencapaian dukungan. Usaha kampanye bisa dilakukan perorangan atau sekelompok orang yang terorganisir untuk melakukan pencapaian suatu proses pengambil keputusan didalam suatu kelompok, kampanye juga bisa dilakukan guna untuk mempengaruhi, penghambatan, pembelokan pencapaian.

Menurut pasal 1 ayat 26 Undang-Undang Nomor 10 tahun 2008 tentang Pemilihan Umum DPR, DPD, DPRD, pengertian kampanye adalah kegiatan peserta pemilu untuk meyakinkan para pemilih dengan menawarkan visi, misi dan program peserta pemilu. Jadi berdasarkan pada 
definisi diatas arti kampanye adalah sebuah purpose to something. Kampanye adalah aktivitas komunikasi yang ditujukan untuk memengaruhi orang lain agar ia memiliki wawasan, sikap dan perilaku sesuai dengan kehendak atau keinginan penyebar atau pemberi informasi (Cangara, 2011). Perilaku keterpilihan kepada daerah pada pilkada dipengaruhi oleh ketokohan kandidat dalam memperoleh suara pada arena politik (Wance, Suhu, 2019).

Sedangkan menurut Imawan (dalam Cangara, 2012) mengungkapkan kampanye adalah upaya persuasif untuk mengajak orang lain yang belum sepaham atau belum yakin pada ide-ide yang kita tawarkan, agar mereka bersedia bergabung dan mendukungnya. Sementara pengertian kampanye yang dikemukakan oleh Kotler dan Roberto (dalam Cangara, 2012) adalah sebagai berikut: "campaign is an organized effort conducted by one group (the change agent) which intends to persuade other (the target adopters), to accept, modify, or abandon certain ideas, attitudes, practices and behavior. (kampanye ialah sebuah upaya yang dikelola oleh satu kelompok, (agen perubahan) yang ditujukan untuk mempersuasi target sasaran agar bisa menerima memodifikasi atau membuang ide, sikap dan perilaku tertentu)".

Kampanye politik termasuk didalamnya kegiatan publisitas adalah sebuah upaya marketing politik.Dalam sebuah pemilihan umum ,marketing politik memiliki peran sentran yang sangat penting karena ia merupakan bagian dari aktivitas pendekatan dalam persuasi kampanye. Kampanye mengemas pesan politik secara intensif dalam kurun waktu tertentu dan dibatasi (Surbakti, 2010). Merujuk pada konsep kampanye yang diungkapkan, maka setiap aktivitas kampanye harus mengandung 4 hal yakni: (1). Tindakan kampanye yang ditujukan untuk menciptkan efek atau dampak tertentu. (2). Jumlah khalayak sasaran yang besar. (3). Biasanya dipusatkan dalam kurun waktu tertentu, dan. (4). Melalui serangkaian tindakan komunikasi yang terorganisasi.

Kaitannya dengan hal diatas mengenai strategi kampanye politik saya mewawancarai ketua DPD partai Golongan Karya Kabupaten Seram Bagian Timur Bapak Agil Rumakat.

"Beliau megatakan bahwa, dalam merencanakan strategi kampanye politik sudah tentunya setiap kandidat dan partai pengusung yang mengkampanyekan kandidat yang diusung harus sesuai dengan model peraturan yang di atur oleh komisi pemelihan umum (KPU), golkar akan laksanakan sepanjang itu tidak bertentangan dengan peraturan, hanya golkar lebih cenderung menonjolkan strategi yang harus di prioritaskan. pada pilkada 2020 kemarin golkar lebih cenderung mengarahkan tim untuk mengkampanyekan secara dor to dor".

"kami bekerja semaksimal mungkin, dalam proses kampanye. selain mepromosikan siapa yang dipilih, dari mana asalnya, bagaimana kulturnya, terlepas dari semua ini kami sangat memprioritaskan visi dan misi dari kandidat partai golkar, sehingga masyarakat dapat menentukan pilihan dan sudah membayangkan setelah kandidat ini terpilih, nanti apa yang dilakukan adalah semua yang terprogram didalam visi dan misi, dan beliau mengatakan bahwa saya yakinmasyarakat menentukan pilihannya kepada pak mukti dan pak idris karena cukup di pengaruhi oleh visi dan misi yang pas atau menjadi target yang ingin dirasakan masyarakat dalam hal ini pembangunan infastruktur dan lain sebagainnya yang menjadi prioritas. (sekretaris partai Golkar, bapak husein).

Hasil wawancara di atas dapat dilihat ada banyak sekali strategi yang digunakan dalam upaya menarik hati pemilih dalam memenangkan pilkada. Strategi-strategi tersebut dalam rangka memberikan pendidikan politik pada masyarakat serta membentuk citra politik yang positif baik bagi partai maupun bagi calon kandidat itu sendiri. Adapun strategi-strategi yang dilakukan salah satunya melalui kegiatan-kegiatan sosial kemasyarakatan seperti pemberian bantuan untuk 
masyarakat fakir dan miskin dan bencana alam, anak yatim, partisipasi dalam kegiatan-kegiatan keagamaan. Pemasangan baliho, spanduk, iklan radio dan Kampanye Politik maupun Sosialisasi kepada simpatisan dan masyarakat umum secara terus menerus, juga menjadi bagian dari strategi Partai Golkar seram bagian timur dalam Memenangkan Pilkada tahun 2020.

\section{Kepemimpinan Adat}

Kepemimpinan merupakan salah satu dimensi kompetensi yang sangat menentukan terhadap kinerja atau keberhasilan organisasi.Esensi pokok Kepemimpinan adalah cara untuk memengaruhi orang lain agar menjadi efektif tentu setiap orang bisa berbeda dalam melakukan. Kepemimpinan merupakan seni, karena pendekatan setiap orang dalam memimpin orang dapat berbeda tergantung karakteristik pemimpin, karakteristik tugas maupun karakteristik orang yang dipimpinnya. Armstrong (2003) menyatakan kepemimpinan adalah proses memberi inspirasi kepada semua karyawan agar bekerja sebaik-baiknya untuk mencapai hasil yang diharapkan. Kepemimpinan adalah cara mengajak karyawan agar bertindak benar, mencapai komitmen dan memotivasi mereka untuk mencapai tujuan bersama (Sudarmanto,2009). Modalitas politik menjadi kekuatan pada arena pemilihan kepala daerah (Wance, Djae, 2019).

Kepemimpinan menurut Anoraga (2003) diartikan sebagai kemampuan seseorang untuk dapat mempengaruhi orang lain, melalui komunikasi baik secara langsung maupun tidak langsung dengan maksud untuk menggerakkan orang-orang tersebut agar dengan penuh pengertian, kesadaran dan senang hati bersedia mengikuti kehendak-kehendak pemimpin itu. Dukungan masyarakat terhadap ketentuan adat saat ini telah terbagi akibat dari perbedaan pendapat. (4) ketaatan masyarakat terhadap seluruh keputusan adat mengalami perubahan akibat dari kepentingan politik (Touwe, Tuanaya, Wance, 2020).

Kepemimpinan menurut Dubrin (2005) adalah upaya mempengaruhi banyak orang melalui komunikasi untuk mencapai tujuan,cara mempengaruhi orang dengan petunjuk atau perintah, tindakan yang menyebabkan orang lain bertindak atau merespons dan menimbulkan perubahan positif, kekuatan dinamis penting yang memotivasi dan mengkoordinasikan organisasi dalam rangka mencapai tujuan, kemampuan untuk menciptakan rasa percaya diri dan dukungan diantara bawahan agar tujuan organisasional dapat tercapai. (Brahmasari Suprayetno, 2008)Berdasarkan pengertian kepemimpinan dari beberapa pendapat ahli diatas, dapat disimpulkan bahwa kepemimpinan erat kaitannya dengan kemampuan seseorang untuk dapat mempengaruhi orang lain agar bekerja sesuai dengan tujuan yang diharapkan.

Kepemimmimpi terbagi menjadi (1). Teori Kelebihan. (2). Teori Sifat. (3). Teori Keturunan. (4). Teori Kharismatik. Teori ini menyatakan bahwa seseorang menjadi pemimpin karena orang tersebut mempunnyai kharisma (pengaruh yang sangat besar) (Wuranto, 2022).

Saya mewancarai ketua DPD partai golkar mengenai tentang kepemimpinan politik.

"terkait dengan kepemimpinan politik incumben dalam keputusan-keputusan politiknya sudah tentunya memperhatikan kepentingan dan aspirasi masyarakat ketika dengan hal ini di lakukan baru adannya simpatisan dari masyarakat. Beliau mengatakan bahwa pak mukti sendiri sebagai calon bupati seram bagian timur, yang di mana latar belakang beliau ada seorang anak adat pernah menjadi pimpinan kepala Adat di kecamatan pulau gorom, desa amarsekarau, dan ini seluruh masyarakat seram bagian timur tahu benar dengan tokoh adat pak mukti, jadi keberpihakan pak mukti pasti mendukung dalam melaksanakan agenda atau kegiatan-kegiatan dalam mengembangkan kearifan lokal, hal ini dilihat pada kegiatan vestifal kataloka yang pernah di lakukan di kecamatan pulau gorom, hal in menjadi bukti pemerintahan pak mukti menaruh perhatian tentang maslah-masalah kearifan lokal". 
Hal demikian di kemukakan oleh ketua bidang informasi dan komunikasi partai golkar mengatakan :

"Bahwa kepemimpinan politik, dimana setiap keputusan-keputusan politik pak mukti sudah tentunya cenderung berorientasi terhadap kesejahteraan masyarakat, pak mukti sebagai tokoh adat, masyarakat percaya, sehingga masyarakat mau ikut di arahkan oleh pemimpin adat, dan sudah tentunnya kepemimpinan politik pak mukti selalu menerjemahkan kepentingan masyarakat.

Berdasarkan wawancara diatas dapat disimpulkan bahwa kepemimpinan Adat Pak Mukti cenderung dalam memperhatikan kepentingan masayarakat Adat, masyarakat Kabupaten Seram Bagian Timur adalah masyarakat yang begitu kental dengan adat istiadat, kandidat yang diusung partai golkar adalah kandidat incumbent beliau adalah sosok tokoh adat yang sudah dikenal oleh seluruh masyarakat Kabupaten Seram Bagian Timur, jadi dalam kepemimpinan Pak mukti sendiri adannya keberpihakan beliau dalam mendukung dan mengembangkan kearifan lokal, dan banyak melantik atau mengkukuhkan para Tokoh Adat di Kabupaten Seram Bagian Timur Sehingga para Tokoh adat di SBT hamoir semua memberikan pikihannya kepada Pak Mukti Keliobas dan Idris Rumalutur.

\section{Kesimpulan}

Setelah melakukan penelitian di DPD II partai golkar kabupaten seram bagian timur, penulis menyimpulkan Partai Golkar menerapkan beberapa strategi pemenangan pada pilkada kabupaten Seram Bagian Timur, di peroleh beberapa kesimpulan sebagai temuan penelitian yaitu :

Realisasi Program Partai yang di tawarkan kepada masyarakat, dimana program partai lebih cenderung berorietasi pada perekonomian masyarakat, seperti di bidang infastruktur, pendidikan dan kesehatan masyarakat. Dalam merealisasikan program-program partai seluruh kader partai golkar baik pada tingkat kabupaten sampai desa bekerja secara maksimal untuk merealisasikan program-program partai, untuk memberikan kepercayaan kepada masyarakat.

Penempatan tokoh atau figur merupakan salah satu pendongkrak, perolehan suara pada setiap konstestasi pemilihan, dimana kemenangan kandidat dari partai golkar pada pilkada seram bagiam timur tahun 2020 sangat di pengaruhi oleh pengaruh dari pada figur yang dicalonkan, calon yang direkomedasikan partai golkar pada pilkada 2020 kemarin,sudah melalui berbagai uji kriteria, dan pak mukti masih dinginkan masyarakat seram bagian timur untuk menjadi bupati pada periodesasi kedepan.

Kampanye Politik Partai golkar sendiri dalam mengkampanyekan figure atau kandidat bupati dan wakil bupati yang di usung pada pilkada 2020 kemarin selain dari pada hal-hal normative, partai golkar lebih cenderung menonjolkan strategi yang harus diprioritaskan, dalam hal ini dengan mengarahkan tim kampanyakan secara dor to dor, visi dan misi dari kandidat yang menjadi target yang menjadi harapan masyarakat, pemasangan baliho dengan berbagai image dan tagline yang cukup strategis dan juga menggunakan pendekatan modern denganmenggunakan peran media Elektronik seperti televisi,radio,dan medsos lainnya dalam mengkampanyekan Program-Program unggulan yang di tawarkan pada periodisasi kedepan dalam hal ini pada aspek pembangunan ekonomi, dibidang infastrukt,pendidikan,kesehatan Sehingga masyarakat juga dapat mengetahui dan memebrikan pilihan kepada kandidat bupati dan wakil bupati.

Kepemimpinan adat, masyarakat Kabupaten Seram Bagian Timur adalah masyarakat yang begitu kental dengan adat istiadat, kandidat yang diusung partai golkar adalah kandidat incumbent beliau adalah sosok tokoh adat yang sudah dikenal oleh seluruh masyarakat kabupaten seram bagian timur, jadi dalam kepemimpinan Pak Mukti Keliobas adannya keberpihakan beliau dalam mendukung dan mengembangkan kearifan lokal seperti, kegiatan festival kataloka, dalam melantik atau mengkukuhkan kepala adat di Seram Bagian Timur, sehingga hampir seluruh kepala

Angar, N. M., Madubun, J., \& Tehuayo, J. (2021). Startegi Pemenangan Partai Golongan Karya Pada Pemilihan Kepada Daerah Kabupaten Seram Bagian Timur Tahun 2020. Journal of Government Science Studies, 1(1). 
adat di Seram Bagian Timur memberikan pilihanya kepada Pak Mukti dan Idris.

\section{Referensi}

Anto Dajan. (1986). Pengantar Metode Statistik II, Penerbit LP3ES, Jakarta Anoraga, Pandji. (2003). Psikologi Kepemimpinan. Jakarta: Rineka Cipta Armstrong dan Philip Kotler. (2003). Manajemen Pemasaran, Edisi Kesembilan. Jakarta: PT.Indeks Gramedia.

Arikunto. (1996). Prosedur penelitian, Rineka Cipta, Jakarta.

Cangara, Hafied. (2011). Pengantar ilmu komunikasi. Jakarta: PT Raja Grafindo. Persada. Dubrin Andrew J., (2005). Leadership (Terjemahan), Edisi Kedua, Prenada Media, Jakarta. Budiarjo, Miriam. (2009). Dasar-dasar Ilmu Politik. Jakarta: PT Gramedia Pustaka Utama. Sudarmanto. (2009). Kinerja dan Pengembangan Kompetensi SDM. Yogyakarta : Pustaka Pelajar Supranto, J. (2000). Teknik Sampling untuk Survei dan Eksperimen. Jakarta: Penerbit PT Rineka Cipta Ramalan Subakti (2010). Memahami Ilmu Politik. Jakarta: PT Gramedia Widiasarana Indonesia

Touwe, M. A., Tuanaya, W., \& Wance, M. (2020). Sistem Pemilihan Raja Negeri Munarten Kecamatan Taniwel Kabupaten Seram Bagian Barat. Jurnal Studi Ilmu Pemerintahan, 1(2), 1-15.

Wance, M., \& Djae, R. M. (2019). Modalitas Dinasti Ahmad Hidayat Mus Pada Pemilihan Kepala Daerah Di Maluku Utara 2018. Sosiohumaniora, 21(3), 256-268.

Wance, M., \& La Suhu, B. (2019). Partisipasi Pemilih Pemula Dalam Menentukan Pilihan Politik Pada Pemilihan Kepala Daerah Maluku Utara.JOURNAL OF GOVERNMENT (Kajian Manajemen Pemerintahan dan Otonomi Daerah), 4(2), 91-115. 